\title{
Metabolic Syndrome in an Aging Society - Role of Oxidant-Antioxidant Imbalance and Inflammation Markers in Disentangling Atherosclerosis
}

\section{Sylwia Dziegielewska-Gesiak (1D)}

Department of Internal Medicine, Medical University of Silesia in Katowice, Bytom, Poland
Correspondence: Sylwia DziegielewskaGesiak

Department of Internal Medicine, Medical University of Silesia in Katowice, Piekarska

$18 \mathrm{Str}$, Bytom, 44-902, Poland

Tel +48601446009

Email sgesiak@sum.edu.p
Introduction: The prevalence of metabolic syndrome among the elderly population is growing. The elements of metabolic syndrome in an aging society are currently being researched. Atherosclerosis is a slow process in which the first symptoms may be observed after many years. The mechanisms underlying the progression of atherosclerosis are oxidative stress and inflammation. Inflammation and oxidative stress are associated with the increased incidence of metabolic syndrome. Taking the above into consideration, metabolic syndrome is thought to be a clinical equivalent of atherosclerosis.

Aim: The aim of this paper is to review the impact of the interplay of oxidant-antioxidant and inflammation markers in metabolic syndrome in general as well as its components in the pathophysiology which underlies development of atherosclerosis in elderly individuals.

Methods: A systematic scan of online resources designed for elderly ( $\geq 65$ years) published from 2005 to the end of 2020 were reviewed. This was supplemented with grey literature and then all resources were narratively analyzed. The analysis included the following terms: "atherosclerosis or metabolic syndrome" and "oxidative stress or inflammation" and "elderly" to find reports of atherosclerotic disease from asymptomatic to life-threatening among the elderly population with metabolic syndrome .

Results: The work summarizes articles that were applicable to this study, including systematic reviews, qualitative studies and opinion pieces. Current knowledge focuses on monitoring the inflammation and oxidant-antioxidant imbalance in disentangling atherosclerosis in patients diagnosed with metabolic syndrome. The population-based studies described inflammation, increased oxidative stress and weak antioxidant defense systems as the mechanisms underlying atherosclerosis development. Moreover, there are discussions that these targets could potentially be a point of intervention to reduce the development of atherosclerosis in the elderly, especially those with altered glucose and lipid metabolism. Specific markers may be used as an approach for the prevention and lifestyle modification of atherosclerotic disease in such population.

Conclusion: Metabolic syndrome and its components are important contributors in the progression of atherosclerotic disease in the elderly population but constant efforts should be made to broaden our knowledge of elderly groups who are the most susceptible for the development of atherosclerosis complications.

Keywords: atherosclerosis, metabolic syndrome, aging, oxidant-antioxidant balance, inflammation

\section{Introduction}

Atherosclerosis has a tremendous impact on health care globally. ${ }^{1}$ The severity of atherosclerosisvaries considerably from asymptomatic to life-threatening organ dysfunction. $^{2-5}$ One of the fundamental elements for establishing prevention, 
treatment and prognosis of atherosclerotic disease is the assessment of clinical forms of the disease. ${ }^{6-10}$ Diabetes mellitus, lipid disorders and/or ischemic heart disease are the clinical exponents of atherosclerosis. ${ }^{11-13}$ During aging metabolic complications and clinical dysfunction accumulate. Furthermore, elderly people are frequently excluded from basic and interventional trials due to high mortality and morbidity.

Atherosclerosis is a slow process, the first symptoms of which are observed after many years. ${ }^{14}$ There is agreement that various mechanisms underlie atherosclerotic disease. The first abnormalities start in the endothelium. The pathogenesis of endothelial injury is induced by two major factors: oxidative stress and inflammation. ${ }^{15,16}$

The disruption in homeostasis of production of reactive oxygen species (ROS) and decreased antioxidant defense systems result in increased oxidative stress. In the elementary model of oxygen-free radical production, the partial reduction of oxygen to water during the electron transport chain in mitochondria is a possible source of oxygen-free radicals, that is, superoxide radicals. Specifically, adequate to the needs, concentration of ROS is substantial to modulate cell metabolism, to act as messengers to promote proliferation, differentiation, immune system regulation, and vascular remodeling, or in the fight against pathogens. ${ }^{17-19}$ However, the over-production of these extremely active particles can damage molecules, cells and tissues. What's more, increased reactive oxygen species production and decreased antioxidant capacity lead to chronic inflammation. $^{20}$

Inflammation plays a crucial role in all stages of the formation of vascular lesions maintained and exacerbated by traditional risk factors (elevated glucose and triglycerides and decreased high density lipoprotein cholesterol concentrations) as well as non-traditional factors (protein glycation, adipocytokines accumulation and nucleic acid damage). ${ }^{21,22}$

This review focuses on the relationship between oxidant-antioxidant and inflammation markers as a potential preventive and therapeutic target for atherosclerosis in elderly individuals suffering from metabolic syndrome (Figure 1). Considerable attention has focused on current knowledge and the advantages of monitoring the inflammation, increased oxidative stress and weak antioxidant defense systems in the elderly patients, especially in those with altered glucose and lipids metabolism. Moreover, the possibility that the discussed markers can be employed as

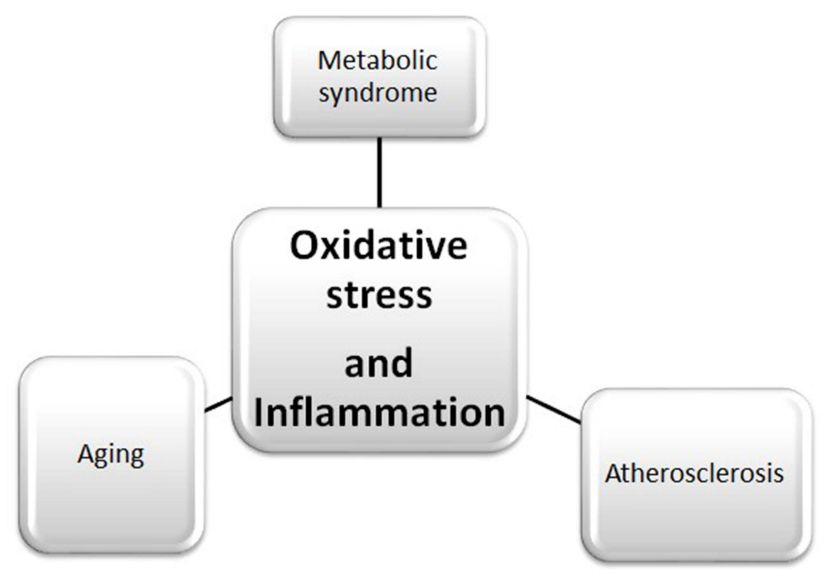

Figure I The relationship between oxidative stress and inflammation and connections to atherosclerosis, aging and metabolic syndrome

a novel approach for the prevention and lifestyle modification of atherosclerotic disease is evaluated.

\section{Methods}

A systematic literature search using the terms "atherosclerosis or metabolic syndrome" and "oxidative stress or inflammation" and "elderly", in order to find reports of atherosclerotic disease from asymptomatic to life-threatening among the elderly population with metabolic syndrome.

Available full texts and the reference lists of the relevant studies were reviewed from the last 15 years, before 2021, by assessing the PubMed and Google Scholar electronic databases. Moreover manually searches for possible missing articles was done. This was supplemented with grey literature and then all resources were narratively analyzed. Repeated articles in other publications or clinical diagnoses of atherosclerosis cases without confirmation were excluded.

\section{Atherosclerosis Mechanisms}

Atherosclerosis is a complex, systemic disease with a multifactorial pathogenesis associated with oxidative stress and inflammatory phenomena. ${ }^{15,20}$ It has been hypothesized that atherosclerosis is associated with systemic, organ, tissue and cellular inflammation. ${ }^{23,24}$

Of particular importance in the development of atherosclerosis, morphologically - both structural and functional is vascular endothelial damage. ${ }^{25}$ Endothelium can be damaged both under the influence of mechanical action, chemicals (catecholamines, nicotine) and under the conditions of harmful biological factors (intrinsic pathophysiological activities or infection). ${ }^{26,27}$ 
In the development of atherosclerotic plaque, the following stages can be distinguished:

- Endothelial cell dysfunction;

- Migration of monocytes to the sub-endothelial layer, their transformation into foam cells and the breakdown of these cells;

- Thrombogenesis and release of growth factors and chemotactic substances from the thrombocytes;

- Migration of myocytes from the middle layer of the vessel to the inner layer, with their subsequent proliferation;

- Formation of intercellular connective tissue. ${ }^{28}$

Atherosclerosis originates from damaged endothelium that allows the accumulation of cholesterol-containing low density lipoproteins (LDL) particles in the arterial wall that tend to be oxidized. ${ }^{29}$ Due to adhesive molecule production in the endothelium monocytes and T-lymphocytes are attached to the endothelial surface. Then, endothelial cells show a proinflammatory phenotype with higher ROS production. However, the vascular endothelium cells are equipped with a variety of antioxidant defense systems enabling the reduction of oxidative burden.

Endothelium releases nitric oxide (NO) synthase and stimulates production of peroxisome proliferator-activated receptor- $\gamma$ coactivator- $1 \alpha$ (PGC- $1 \alpha){ }^{30,31}$ The anti-atherosclerotic effect mediated by NO targets the mitochondrial electron transport chain to reduce levels of ROS or depends on directly scavenging of superoxides. ${ }^{15}$ PGC$1 \alpha$ regulates transcription of genes in both the nucleus and the mitochondria that combat ROS production thereby inhibiting oxidative damage caused by superoxides and thus limiting endothelial dysfunction. ${ }^{32,33}$ Moreover PGC- $1 \alpha$ in time-dependent manner acts with nitric oxide. The NO donors act to downregulate levels of PGC- $1 \alpha$ in less than 12 hours, whereas longer-term they have the opposite effect. $^{34}$

Furthermore, antioxidant enzymes may also enhance oxidative stress when the capacity of downstream enzymes (catalase and glutathione peroxidase) is insufficient to detoxify superoxides enzymes. ${ }^{35}$ Moreover, migration of leukocytes through the endothelium is mediated by the cytokine - monocyte chemoattractant protein-1 (MCP-1). Monocytes in the intimal space of the vessel capture the modified lipoprotein molecules, transform into foam cells, and then begin to produce cytokines and matrix metalloproteinases (MMPs). MMPs play a significant role in plaque rupture, parietal thrombosis and the occurrence of acute coronary syndromes. ${ }^{36}$

\section{Metabolic Syndrome and Its Components - the Clinical Equivalent of Atherosclerosis}

Metabolic syndrome (MetS) brings the most dangerous risk factors for atherosclerosis development. It is estimated that it affects about a quarter of the world's adult population. People with the syndrome are five times more likely to develop type 2 diabetes (if it is not yet diagnosed) 3-fold higher risk to have an acute coronary episode or infarction and 2 times more likely to die in comparison with those individuals without metabolic syndrome. ${ }^{37}$

Since 2009, metabolic syndrome has been defined by joint scientific statement as a presence of three out of five abnormal findings:

- Central obesity with waist circumference (WC) $\geq 94 \mathrm{~cm}$ in men and $\geq 80 \mathrm{~cm}$ in women;

- Elevated triglycerides (TG) $\geq 150 \mathrm{mg} / \mathrm{dL} \quad(1.7$ $\mathrm{mmol} / \mathrm{L})$;

- Reduced HDL-cholesterol (HDL-C): $<40 \mathrm{mg} / \mathrm{dL}$ $(1.03 \mathrm{mmol} / \mathrm{L})$ in men and $<50 \mathrm{mg} / \mathrm{dL}(1.3 \mathrm{mmol} / \mathrm{L})$ in women;

- Elevated blood pressure (BP): systolic BP $\geq 130$ $\mathrm{mmHg}$ or diastolic $\mathrm{BP} \geq 85 \mathrm{mmHg}$ or diagnosed hypertension;

- Elevated fasting glucose $\geq 100 \mathrm{mg} / \mathrm{dL}$ or diagnosed diabetes. $^{38}$

It was described that inflammation and oxidative stress were associated with generally increased incidence of metabolic syndrome, ${ }^{39,40}$ as well as its elements. ${ }^{41-43}$ In postmenopausal women increased $\mathrm{C}$-reactive protein (which reflects inflammation) and increased thiobarbituric acid reactive substances (TBARS) and carbonyls (which reflect oxidative stress) and decreased catalase activity (which reflect antioxidant defense), were observed. ${ }^{44}$ However, in the middle aged and elderly population, multivariate logistic regression analysis revealed that xanthine oxidoreductase (XOD), malondialdehyde (MDA) and advanced oxidation protein products (AOPP) were the independent predictors of MetS, whereas no association between nitric oxide products (NOx) and MetS was found. ${ }^{45}$

What is more, low-grade inflammation, increase in adiposity, insulin and leptin resistance are associated with 
variations in gut microbiota composition, and its derived products, and lead to a clinical picture of metabolic syndrome. ${ }^{46}$ Yet, in healthy adults the composition of microbes is relatively stable (defined as eubiosis), however, environmental changes, sedentary lifestyle, diet style, also aging can cause a constant change in the diversity and/or abundance of individual taxonomic groups of bacteria, leading to dysbiosis in the human body. ${ }^{47-49}$

\section{Obesity}

Obesity measured by waist circumference is called central or abdominal obesity. In clinical trials, a positive correlation was found between waist circumference and fasting insulin concentration, insulin resistance and the incidence of cardiovascular events. ${ }^{50,51}$ However, abdominal obesity is not included in most cardiovascular disease risk assessments. The excess body fat impairs hemodynamic function, disturbs redox homeostasis, and provokes proinflammatory responses. ${ }^{52,53}$

Central obesity is characterized by a change in the size of fat cells and tissue infiltration by monocytes. Adipocytes and infiltrating cells (macrophages) produce adipocytokines, which are involved in the control of nutrition, regulation of insulin sensitivity and carbohydratelipid metabolism, modulation of inflammatory processes, hemostasis and angiogenesis. ${ }^{54}$ Altered adipocytokines secretion is seen in obese individuals. Leptin is an adipokine produced by adipocytes in proportion to the amount of body fat, even in the extremely elderly. ${ }^{55}$ Another adipokine is adiponectin, which decreases in obese patients. Together with waist circumference these serve as predictors of insulin-resistance even in non-diabetic women. ${ }^{56}$ Apart from that, positive correlation of adiponectin with high density lipoprotein cholesterol (HDL-C) was highly prevalent among overweight/obese Emirati women together with a positive correlation of highly sensitive C-reactive protein (hsCRP) with body fat as well as with waist circumference and the positive correlation of interleukin-6 (IL-6) with waist circumference. ${ }^{57}$ However, in 60 -year-old patients, described by Holewijn et al., the association of adiponectin level was not dependent on other cardiovascular factors and only waist circumference showed independent associations with increased pulse wave velocity (PWV), intima media thickness (IMT) and increased plaque thickness - the non-invasive measurements of subclinical atherosclerosis. ${ }^{58}$

It has been reported that obesity - particularly abdominal obesity - increases systemic inflammation and oxidative stress. Furthermore, inflammation in obese elderly persons induces tumor necrosis factor $\alpha$ (TNF $\alpha)$ ligand superfamily member 9 , producing $\mathrm{THF} \alpha$, interferon $\gamma$ (IFN $\gamma)$ and granzyme B cells. ${ }^{59}$ Additionally, IFN $\gamma$ is also secreted by $\mathrm{T}$ lymphocytes which infiltrate abdominal tissue and stimulates the production of several chemokines from adipocytes which induce redox imbalance. It was found that TNF $\alpha$ is increased in obese, otherwise healthy individuals in comparison with lean individuals. ${ }^{60}$ Other researchers also confirmed involvement of TNF $\alpha$ in the pathophysiology of atherosclerosis and obesity-related insulin resistance. ${ }^{61,62}$ Furthermore, Efremov showed that phenotype of metabolically healthy but obese elderly is associated with cardiac remodeling: increased left ventricular mass index and left atrium volume and higher left atrium diameter as well as higher odds ratios for inflammatory biomarkers hsCRP, IL-6 and soluble tumor necrosis factor receptor I (sTNF-RI) compared with metabolically healthy, normal weight individuals. $^{63}$ Moreover, obesity and insulin resistance are associated with dysbiosis (a lower proportion of Bacteroidetes and a higher proportion of Firmicutes) which may induce low-grade inflammation. ${ }^{64}$

Increased systemic oxidative stress in obesity has been described by Yadav et al. They revealed progressive intensification of cardiovascular disease in metabolic syndrome patients in which was found absolute reduction of glutathione (GSH) and superoxide dismutase (SOD) - intracellular antioxidants and increased involvement of lipid peroxidation. $^{65}$ Moreover, it was shown that total antioxidant capacity, and concentration of antioxidants (vitamin $\mathrm{C}$ and vitamin $\mathrm{E}$ ) were lower both in young and older obese patients compared with lean controls. In addition, catalase and SOD activities were reduced in obese older men, but increased in obese younger patients, while activity of glutathione peroxidase was decreased in obesity irrespective of age. ${ }^{66}$

\section{Triglycerides and High Density Lipoproteins-Cholesterol}

It is known that the obese individuals have higher plasma triglyceride (TAG), total cholesterol (TC), low density lipoproteins cholesterol (LDL-C), and diminished high density lipoproteins cholesterol (HDL-C) compared with lean controls. ${ }^{67}$ Endothelium damage may originate from the accumulation of improper lipids metabolism which triggers an inflammatory response that fails to resolve. ${ }^{68}$ 
In the study of Rizzo et al. the multivariate analysis revealed a synergistic role of low-HDL-cholesterol concentration and inflammation (measured by C-reactive protein and fibrinogen) on the atherosclerosis progression from subclinical lesions to clinical events. ${ }^{69}$ However, the study conducted by El Khoudary showed that aging modified the relationship of large HDL-particles (rather than HDL-cholesterol) with carotid intima media thickness (cIMT) and moreover increased large HDL-particles were related with increased cIMT close to menopause but with lower cIMT later in life. ${ }^{70}$

The ratio of TAGs and HDL-C (TAG/HDL-C) theoretically reflects the balance between risk and protective lipoprotein forces. ${ }^{71}$ These lipids, together with TC and LDL-C, are considered an important cardiometabolic risk factor for the development of atherosclerosis. ${ }^{72}$ Moreover, the TC/HDL-C ratio, known as Castelli index, (TC-HDLC)/HDL-C index called atherogenic index (AI) and the TAG/HDL-C ratio are important components and indicators of vascular risk, the predictive value of which is greater than the isolated parameters. ${ }^{73}$ In addition, logarithmic transformation of the TAG/HDL-C ratio, called the atherogenic plasma index (AIP), is closely associated with particle size of HDL, LDL and very low density lipoproteins (VLDL) as well as mediating the balance between atherogenic and protective lipoproteins. ${ }^{74}$ However, the meta-analysis carried by Zhu et al. suggests that AIP index may be more closely associated with the risk of type 2 diabetes mellitus. ${ }^{75}$

Furthermore, lipid metabolism disturbances in coronary atherosclerosis were accompanied by changes not only in lipid spectrum but also increased concentrations of saturated fatty acids, CRP and interleukins: IL-6, IL-8. ${ }^{76}$ Additionally, in a large cohort of European adults, the oddchain saturated fatty acids was inversely associated with CRP and Castelli index. In contrast, there were positive associations between the even-chain saturated fatty acids and CRP and lipids: triglycerides, low density lipoproteincholesterol, Castelli index and inverse associations with high density lipoprotein-cholesterol. ${ }^{77}$

A study conducted by Hadj revealed that a high level of trans fatty acids was not only associated with lowdensity lipoprotein-cholesterol/high-density lipoprotein cholesterol (LDL-C/HDL-C) ratio, and apolipoprotein $\mathrm{B}$ (ApoB) but also with the induction of inflammation and consequently atherosclerosis disease confirmed by the positive correlations between inflammatory markers (IL-6, hs-CRP) and vascular severity (Gensini score) and increased oxidative stress measured by malondialdehyde which reflect lipids peroxidation. ${ }^{78}$ Moreover, using the Gensini score, it was found that in subjects at high risk of coronary artery disease, including those over 60 years, the polymorphisms in antioxidant genes of superoxide dismutase family (SOD2 rs4880, SOD3 rs2536512 and rs2855262) are related with hypertriglyceridemia and low HDL-C independently. ${ }^{79}$ Furthermore, low HDL-C concentration was associated with elevated TBARS in a case-control study of elderly individuals. ${ }^{80}$ Also, low HDL-C correlates with paraoxonase-1 (PON-1) (which is a marker of atherosclerosis) in already atherosclerotic patients. $^{81}$

In that context researchers reconciled that healthy aging may be maintained through proper lipid balance and adequate oxidant-antioxidant control. Yet, the investigation conducted by Dzięgielewska-Gęsiak supported the premise that the equilibrium in lipid metabolism and oxidant-antioxidant status are essential to comprehend the evolution of senescence as well as the progression of chronic conditions - which atherosclerosis is ${ }^{80}$ There are also mathematical models, which show how the combination of the concentrations of: lipids - TAG, HDL-C LDL$\mathrm{C}$; oxidative markers - oxidized LDL particles and free radicals or MMPs; cytokines - MCP-1, IFN, interleukines; and cells - T and B cells, macrophages, foam cells and smooth muscle cells which may determine the formation of an atherosclerotic plaque and thus could help in choosing the best targeted therapy. ${ }^{82,83}$

\section{Hyperglycemia}

Paun and Danska observed that in the last 50 years, the significant rise in the incidence of diabetes is associated with the influence of the composition and function of the gut microbiome on autoimmune responses directed against pancreatic cells, insulin resistance and obesity. ${ }^{84}$ What is more, inflammation has been considered a hallmark in the pathogenesis when hyperglycemia persists with an activation of the immunity in adipose tissue. ${ }^{85}$ On the other hand, chronic adipose tissue inflammation contributes by adipocytokines secretion to systemic insulin resistance which is caused by hyperglycemia and to endothelial dysfunction - the first step in atherosclerosis. ${ }^{86}$

In a cross-sectional study of elderly individuals with impaired fasting glucose and/or impaired glucose tolerance it was found that there was decreased adiponectin concentration, increased interleukins (IL-1 $\alpha$, IL-4, IL-6, IL-8, IL17) and $\mathrm{TNF} \alpha$ concentration in comparison with normal 
glucose-tolerant elderly individuals while MCP-1, E-selectin, and adhesion molecules (vascular cell adhesion molecule-1 (VCAM-1) and intercellular adhesion molecule-1 (ICAM-1)) were unchanged. ${ }^{87}$ After an adjustment for waist circumference the significance persists for IL-4, $\mathrm{TNF} \alpha$, and VEGF, indicating that inflammation is evident in elderly prediabetic patients.

Moreover, it was found that occulted impairment of glucose metabolism was associated with adiponectin and the presence of more vascular areas affected. ${ }^{88}$ In addition, in already diagnosed patients who had atherosclerosis with diabetes, the TNF $\alpha$ and IL- 6 were significantly increased in comparison with those with diagnosed atherosclerosis without diabetes. ${ }^{89}$

Taking into consideration oxidant-antioxidant balance and anti-inflammatory potential of HDL function, it was reported that hyperglycemia reduces the HDL protective effect which accelerates the process of atherosclerosis. ${ }^{90,91}$ Ebtehaj et al. described decreased HDL anti-inflammatory capacity, which was determined as the ability to suppress TNF- $\alpha$ induced VCAM-1 mRNA expression in endothelial cells in vitro. ${ }^{92}$ However, the HDL anti-inflammatory capacity was impaired in the context of chronic hyperglycemia, independently of HDL-cholesterol concentration. Moreover, Hernaez et al. argued that both diabetes and advanced age were related to the increased LDL oxidation and triglyceride content in LDL particles. In patients with diabetes lower LDL resistance against oxidation and in aged patients increased LDL cytotoxic potential were observed which all in all indicate increased pro-atherogenic properties. ${ }^{93}$

Furthermore, the study conducted by DzięgielewskaGęsiak indicated that in elderly prediabetic patients there were lower SOD-1 activity and total antioxidant status which may be considered the first symptoms of oxidative stress. $^{94}$

Another clinical study of patients with diabetes revealed preclinical structural and functional cardiac damage (measured by inter-adventitial diameter, carotid wave speed, carotid-femoral pulse wave velocity and left ventricular mass) independently linked with increased concentration of plasma interleukins (IL-6, IL-18) and matrix metalloproteinase-12 and with substantial decrease in HDL-C. ${ }^{95}$

\section{Hypertension}

It was seen that high blood pressure promotes inflammation in the arterial wall and exerts oxidative stress. ${ }^{96}$ In patients with untreated essential hypertension, an increase in TBARS and the stable end products of nitric oxide (NOx) concentration in plasma was found. It confirms that hypertension is accompanied by an oxidative stress and inflammatory response. ${ }^{97}$ Furthermore, serum zinc, copper and magnesium concentration and enzymatic and non-enzymatic antioxidants were significantly decreased, while TBARS and $\mathrm{C}$-reactive protein were increased in prehypertensives, stage I and II hypertensives in comparison with normotensive individuals. ${ }^{98}$ Also, parallel to the decline in total antioxidant status the arterial elasticity was decreased while arterial stiffness was raised in elderly hypertensive patients. ${ }^{99}$ From a clinical point of view the morning increase in blood pressure was independently associated with the reduction of antioxidant paraoxonase-1 (PON-1) activity. ${ }^{100}$ Moreover, in individuals with hypertension, oxidative stress promotes endothelial dysfunction by superoxide dismutase-1 which was found to be negatively associated with pulse wave velocity. ${ }^{101}$

In a case-control study, the hypertensive patients with insulin resistance manifested a significantly higher atherogenic index of plasma $(\log [\mathrm{TAG}] / \mathrm{HDL}-\mathrm{C})$ and a lower adiponectin concentration compared with hypertensive, insulin sensitive patients and healthy controls. ${ }^{102}$ Taking into account inflammation, angiopoietin-2 (Ang-2) has been found to be an essential endothelial-specific facilitator of vascular responsiveness to inflammatory stimuli. In elderly hypertensive patients and those with existing atherosclerosis, the concentration of Ang-2 was elevated and moreover significantly correlated with IL-6, VCAM-1 and ICAM-1. ${ }^{103}$

On the other hand, the Multi-Ethnic Study of Atherosclerosis (MESA) showed that IL-6 and CRP have a significance in the development of hypertension. Moreover, the combination of being obese with increased CRP concentration (CRP $\geq 3 \mathrm{mg} / \mathrm{l}$ ) was associated with higher risk for developing hypertension as opposed to being obese with good CRP levels $(<1 \mathrm{mg} / \mathrm{l}) .{ }^{104}$ Moreover, the meta-analysis demonstrated that elevated CRP, hs-CRP and IL- 6 , but not IL-1 $\beta$, were associated with the risk of hypertension development. ${ }^{105}$ What is more, Takagi et al. showed increased levels of the Actinobacteria phylum in patients with hypertension, dyslipidemia, and hyperglycemia, and this increase was reflected in the increased abundance of the Bifidobacterium genus. ${ }^{106}$ 


\section{Age-Related Body Composition Changes Related to Oxidant-Antioxidant Balance and Inflammation}

Biological healthy aging is defined as the natural occurrence of irreversible, increasing with age changes in metabolism which lead to impaired self-regulation and regeneration, structural and functional changes in cells, tissues and/or organs. ${ }^{107}$ Harman advanced the hypothesis of free radicals aging theory. The theory is based on oxidant-antioxidant imbalance during aging which is caused by the damage of cells by free radicals as well as improper antioxidant defense system - the repair processes by existing enzymes. ${ }^{108}$ Research on the influence of free radicals on the aging processes and its relevance has been widely discussed in this century. The imbalance in the oxidant and antioxidant system may lead to changes in body composition.

It is evident that all organs experience some changes in tissue composition through lifespan. These age-related changes are directly connected with sub-clinical and clinical pathology which lead to insulin-resistance, demineralization, muscle mass loss and loss of bone strength. ${ }^{109,110}$ Moreover, during aging age-related changes in body composition especially in skeletal muscle and fat mass are widely observed. The volume of total body water tends to decline while the muscle mass reduction is accompanied by an increase in fat mass. ${ }^{111}$ The decrease in skeletal mass and the increase of fat mass influence the insulin sensitivity, glucose uptake by muscles and finally obesity-related complications associated with oxidative and endoplasmic reticulum stress and induces inflammation. ${ }^{112}$

There is a cross-link between aging and atherosclerosis development. Nitric oxide (NO), endothelial nitric oxide synthase (eNOS) were significantly decreased, whereas $\mathrm{O}_{2}^{-}$(superoxide anion radical) and the pro-oxidant enzyme NADPH oxidases system were highly activated in aging cells ${ }^{113,114}$ Moreover, the NADPH oxidases system is a major source of oxidative stress and is highly upregulated in the endothelium in response to environmental challenges and diseases. ${ }^{115}$ In addition, in animal models the increase in NADPH oxidases activity in endothelial cell presages plaque progression and chronic inflammation. ${ }^{116}$ Yet, reduced eNOS occurs in response to proinflammatory signals. ${ }^{117}$
To counteract increased oxidative stress, various antioxidant systems exist both at the enzymatic and non-enzymatic levels. The decrease in expression and activity of peroxisome proliferator-activated receptor $\gamma$ coactivator- $1 \alpha$ (PGC- $1 \alpha$ ), which regulates mitochondrial genes expression of antioxidant enzymes (superoxide dismutase-2 (SOD-2), catalase (CAT), peroxiredoxin 3 and 5 ( $\operatorname{Prx} 3$ and 5) and thioredoxin (TRX)), was associated with accelerated vascular aging and atherosclerosis. ${ }^{118}$ In addition, the inhibited antioxidant enzymes, which are located in the cytosol (superoxide dismutase-1 (SOD-1), glutathione peroxidase (GPx), or heme oxygenase-1 (HO-1)), up-regulate ROS production and thus accelerate senescence and atherosclerosis. ${ }^{119,120}$ Moreover, in insulin-resistant elderly patients insulin action, via oxidant-antioxidant imbalance identifies those at high risk of atherosclerosis, while healthy aging is connected with increased oxidative stress. ${ }^{121}$

\section{Preventing Atherosclerosis Through Metabolic Syndrome Components Modification}

Randomized controlled trials focused on the evaluation of the comparative efficacy of lifestyle, dietary and medical intervention, inflammation and oxidative stress in individuals with metabolic syndrome and its components. In Indian adults with metabolic syndrome a 12-week yogabased lifestyle intervention showed significantly greater reduction in TBARS levels as opposed to the dietary intervention group. Moreover, the yoga intervention had a positive impact on inflammatory response (reduction in IL-6) as well as antioxidant defense system (increase in SOD). ${ }^{122}$

Furthermore, annual rates of change $(\Delta)$ in dairy calcium and phosphorus intake were inversely related to HDL-C dyslipidemia and MetS incidents, while $\Delta$ dairy fat was positively associated with incidence of hypertriglyceridemia and HDL-C dyslipidemia and MetS incidence. $^{123}$

It was also shown that dietary intervention by the intake of monounsaturated fatty acids (MUFA) and polyunsaturated fatty acids (PUFA) were associated with a lower risk of cardiovascular disease (CVD) incidence and death, whereas saturated fatty acids (SFA) and transfat intakes were associated with a higher risk of CVD. ${ }^{124}$ In the management of metabolic syndrome patients, the extract of fruits of Phyllanthus emblica taken twice daily significantly improved lipids, reduced oxidative stress and 
increased antioxidant enzymes activity as well as NO production and reduced systemic inflammation and thus endothelial function. ${ }^{125}$

From the molecular point of view, studies have uncovered the various mechanisms through which a diet rich in antioxidant nutrients affects development of metabolic disturbances that lead to atherosclerosis. For instance resveratrol stimulates autophagy via the AMP-activated protein kinase (AMPK)-mTOR signaling pathway, has an impact on the nuclear factor $\kappa \mathrm{B}(\mathrm{NF}-\mathrm{\kappa B})$ signaling pathway and acts on peroxisome proliferator-activated receptor- $\gamma$ coactivator- $1 \alpha$ (PGC- $1 \alpha)$, and therefore might be a promising therapeutic agent for metabolic syndrome. ${ }^{126-128}$

\section{Obesity}

Caloric restriction leading to weight loss combined with aerobic exercise proved to be the most effective in improving functional status of obese older adults. ${ }^{129,130}$ Furthermore, caloric restriction in patients with morbid obesity significantly improved lipids and inflammation status as well as insulin sensitivity. ${ }^{131}$

Moreover, in an animal model, a diet rich in resveratrol prevented sarcopenic obesity by reversing mitochondrial dysfunction and oxidative stress, which was mediated by the AMP kinase pathway. ${ }^{132}$

Furthermore, in elderly obese individuals exercise training reversed insulin resistance through improvement of resting substrate oxidation and promotion of lipid utilization in skeletal muscles. ${ }^{133}$

\section{TAG and HDL-C}

In animal models, it was found that treating mice with polyphenol-rich pomegranate juice (PJ) or ingestion of recombinant paraoxonase1 (rePON1) decreased the serum concentration of TBARS $(16 \%$ and $19 \%$ respectively) and triglycerides (24\% and $27 \%$ respectively). Moreover, both PJ and rePON1 significantly decreased aortic cholesterol (38\% and 32\% respectively) and triglyceride (62\% and $58 \%$ respectively) content, while only PJ decreased aortic lipid peroxides. The TAG-lowering effects of both PJ and rePON1 were observed also in the heart, liver ( $34 \%$ and $42 \%$ ), and kidney ( $42 \%$ and $57 \%$ ). In both visceral and subcutaneous adipose tissues rePON1 ingestion decreased the levels of TBARS $(28 \%$ and $25 \%$ ), while PJ effecs lead to a decrease in TAG content in the adipose tissue $(22 \%$ and $18 \%) .{ }^{134}$ On the other hand the consumption of oxysterols - the oxidized cholesterols - leads to cytotoxic effect on vascular endothelial cells, causing endothelial dysfunction, the severity of which depends on the duration of exposure. At the same time, the inflammatory response and dyslipidemia increase in severity. ${ }^{135}$

In MetS patients a combination of red yeast rice and olive fruit extract improved the lipid profile and reduced LDL oxidation. ${ }^{136}$ Moreover, the natural compound berberine in combination with a sirtuin 1 activator - resveratrol could be an effective therapy for hyperlipidemia in type 2 diabetes and MetS. The enhanced effect on lipidlowering may be associated with upregulation of lowdensity-lipoprotein receptor. ${ }^{137}$

Concerning exercise, high-intensity intermittent exercise is better than walking and reduces postprandial TAG. It is associated with suppression of the postprandial increase in TBARS. ${ }^{138}$

\section{Hyperglycemia}

A randomized control trial on impaired glucose tolerant patients with coronary artery disease, after 6 months of treatment by eicosapentaenoic acid (EPA), the omega-3 fatty acid, showed an improvement in fasting TAG and HDL-C concentration and moreover positive changes in postprandial glycemic and triglyceridemic control and in secondary outcomes decrease in insulin resistance, while the lipids correction was an independent predictor of endothelial recovery. ${ }^{139}$ However, in patients with metabolic syndrome who used Açaí (Euterpe oleracea Mart.) berries for over 12 weeks, improved only biomarkers of inflammation and oxidative stress while they did not change lipids and glucose concentration. ${ }^{140}$

Exercises significantly influenced the relationship between diurnal oxidative stress and nocturnal glycemic variability in individuals with both impaired glucose tolerant individuals as well as type 2 diabetes mellitus patients. ${ }^{141}$

\section{Hypertension}

In a randomized, double-blind, placebo-controlled clinical trial the fortification diet with daily blueberry reduced blood pressure and arterial stiffness, due to inflammation reduction in vessels. ${ }^{142}$ Furthermore, chronic treatment with paeonol ((2'-hydroxy-4'-methoxyacetophenone), the major compound from the root bark of Paeonia suffruti$\cos a$ ) has preserved endothelial function and normalized blood pressure through improved NO bioavailability and inhibition of associated endoplasmic reticulum stress. ${ }^{143}$ 
Table I Lifestyle and Dietary Modifications in Metabolic Syndrome and Its Components

\begin{tabular}{|l|l|l|l|}
\hline & Diet Intervention & Exercise Intervention & Reference \\
\hline MetS & $\begin{array}{l}\text { Reduction in MDA } \\
\text { Increase in NO and GSH } \\
\text { Reduction in hSCRP }\end{array}$ & $\begin{array}{l}\text { Reduction of TBARS } \\
\text { Increase in SOD } \\
\text { Reduction in IL-6 }\end{array}$ & {$[122$, I25-I28] } \\
\hline Obesity & Reduction in IL-6 & Oxidation decrease & {$[131,133]$} \\
\hline Hyperglycemia & Reduction in IFN $\gamma$ and 8-isoprostane & Reduction in isoprostanes & {$[140,14 I]$} \\
\hline Hypertension & Increase in NO & Increase in SOD and GSH & {$[142-144]$} \\
\hline HDL-C and TAG & Reduction in oxLDL & Reduction in TBARS & {$[136,138]$} \\
\hline
\end{tabular}

Moreover, it was proved that low intensity aerobic exercise in hypertensive elderly women improved oxidant-antioxidant balance. ${ }^{144}$

\section{Perspectives and Challenges}

As shown in this study in individuals with metabolic syndrome, the development of atherosclerosis is governed by environmental reasons (a hyper-caloric diet and/or lack of physical activity, and the consequent increased adiposity and obesity) as well as host-related factors (age, oxidant-antioxidant balance and inflammatory responses).

On the other hand, dietary or exercise interventions reduce oxidative stress, inflammation and thus reduce atherosclerosis risk even in an elderly population. Interestingly, it was observed not only on the clinical but also on the molecular level. ${ }^{145}$ The beneficial effects of the Mediterranean diet, which contain polyphenols, include mechanisms underlying the reduction of ROS-mediated activation of NF- $\mathrm{kB}$, influence on enzymes: cyclooxygenase-2 (COX-2) and matrix metalloproteinases (MMPs). ${ }^{146}$ In addition, in the animal model it was proved that diet rich in antioxidants, such as curcumin, enhances catalase activity and strongly down-regulates the expression of

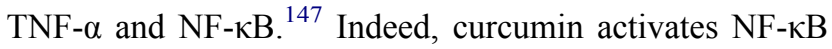
which suppresses expression of adipocytokines, chemokines (MCP-1, MCP-4) and interleukins (IL-1, IL-6, IL8) and down-regulates inflammatory biomarkers, such as COX-2 and vascular endothelial growth factor (VEGF). ${ }^{148,149}$

Thus, researches mentioned earlier, which include elderly individuals, in disentangling atherosclerosis brings tremendous perspectives for healthy longevity (Table 1).

However, the question arises what challenges should be posed to reduce the number of people exposed to oxidative stress, inflammation and thus atherosclerosis development. First of all, it is necessary to educate from youth in order to change eating habits and lifestyle. Moreover, the education cannot stop at the level of the younger generation. It is necessary to educate elderly individuals. Realizing the importance of changing diet and lifestyle should lead to the reduction in the number of atherosclerosis cases. For education to be effective, it is necessary to build educational programs both on a national and worldwide level. Only wide-ranging and varied activities can bring about the expected results. Therefore, building such programs requires the involvement of both science and state structures.

\section{Summary}

As previously mentioned, considerable attention has been directed to inflammatory and oxidative markers in disentangling atherosclerosis among elderly patients with metabolic syndrome. Despite tremendous progress in interventions in the metabolic syndrome population, constant efforts should be made to broaden our knowledge of elderly groups who are the most susceptible to the development of atherosclerosis complications. Oxidative stress and inflammation in atherosclerosis are discrete biochemical conditions, perhaps one of the greatest opportunities for intervening earlier or with prevention or lifestyle changes even in an elderly population.

\section{Disclosure}

The author declares no conflict of interest.

\section{References}

1. GBD 2015 Mortality and Causes of Death Collaborators. Global, regional, and national life expectancy, all-cause mortality, and causespecific mortality for 249 causes of death, 1980-2015: a systematic analysis for the Global Burden of Disease Study 2015. Lancet. 2016;388:1459-1544. 
2. Salari A, Shakiba M, Mahdavi-Roshan M, et al. The association between various indices of obesity and severity of atherosclerosis in adults in the north of Iran. Medicine. 2016;95(50):e5670. doi:10.1097/MD.0000000000005670

3. Ambale-Venkatesh $\mathrm{B}$, Yang $\mathrm{X}, \mathrm{Wu} \mathrm{CO}$, et al. Cardiovascular Event prediction by machine learning: the Multi-Ethnic Study of Atherosclerosis. Circ Res. 2017;121(9):1092-1101. doi:10.1161/ CIRCRESAHA.117.311312

4. Klisić A, Kavarić N, Bjelaković B, et al. Cardiovascular risk assessed by reynolds risk score in relation to waist circumference in apparently healthy middle-aged population in Montenegro. Acta Clin Croat. 2018;57:22-30. doi:10.20471/acc.2018.57.01.03

5. Gao X, Song J, Watase H, et al.; on behalf of CARE-II Investigators. Differences in carotid plaques between symptomatic patients with and without diabetes mellitus, A CARE-II Study. Arterioscler Thromb Vasc Biol. 2019;39(6):1234-1239. doi:10.1161/ATVBAHA.118.312092

6. Ouchi Y, Sasaki J, Arai H, et al. Ezetimibe Lipid-lowering trial on prevention of atherosclerotic cardiovascular disease in 75 or older (EWTOPIA 75): a randomized, controlled trial. Circulation. 2019;140(12):992-1003. doi:10.1161/ CIRCULATIONAHA.118.039415

7. Mortensen MB, Nordestgaard BG. Statin use in primary prevention of atherosclerotic cardiovascular disease according to 5 major guidelines for sensitivity, specificity, and number needed to treat. JAMA Cardiol. 2019;4(11):1131-1138. doi:10.1001/jamacardio.2019.3665

8. Lloyd-Jones DM, Braun LT, Ndumele CE, et al. Use of risk assessment tools to guide decision-making in the primary prevention of atherosclerotic cardiovascular disease: a special report from the American Heart Association and American College of Cardiology. Circulation. 2019;139(25):e1162-e1177. doi:10.1161/CIR.0000000000000638

9. Lee MMY, Sattar N, McMurray JJV, Packard CJ. Statins in the prevention and treatment of heart failure: a review of the evidence. Curr Atheroscler Rep. 2019;21(10):41. doi:10.1007/ s11883-019-0800-z

10. Liu D, Liu J, Cai Y, et al. Is the future of symptomatic intracranial atherosclerotic stenosis management promising? J Neurol Neurosurg Psychiatry. 2020;91(2):122-124. doi:10.1136/jnnp2019-321564

11. Nelson AJ, Peterson ED, Pagidipati NJ. Atherosclerotic cardiovascular disease and heart failure: determinants of risk and outcomes in patients with diabetes. Prog Cardiovasc Dis. 2019;62 (4):306-314. doi:10.1016/j.pcad.2019.07.001

12. Lamprea-Montealegre JA, Zelnick LR, Hall YN, et al. Prevalence of hypertension and cardiovascular risk according to blood pressure thresholds used for diagnosis. Hypertension. 2018;72 (3):602-609. doi:10.1161/HYPERTENSIONAHA.118.11609

13. Sundbøll J, Larsen AP, Veres K, et al. Cardiovascular event rates and trajectories of LDL-cholesterol levels and lipid-lowering therapy in patients with atherosclerotic cardiovascular disease: a population-based cohort study. Thromb Res. 2019;183:124-130. doi:10.1016/j.thromres.2019.09.034

14. Cakmak HA, Aslan S, Gul M, et al. Assessment of the relationship between a narrow fragmented QRS complex and coronary slow flow. Cardiol J. 2015;22(4):428-436. doi:10.5603/CJ.a2015.0007

15. Förstermann U, Xia N, Li H. Roles of vascular oxidative stress and nitric oxide in the pathogenesis of atherosclerosis. Circ Res. 2017;120(4):713-735. doi:10.1161/CIRCRESAHA.116.309326

16. Wu MY, Li CJ, Hou MF, Chu PY. New insights into the role of inflammation in the pathogenesis of atherosclerosis. Int $\mathrm{J} \mathrm{Mol} \mathrm{Sci}$. 2017;18(10):2034. doi:10.3390/ijms18102034

17. Wang Y, Zang QS, Liu Z, et al. Regulation of VEGF-induced endothelial cell migration by mitochondrial reactive oxygen species. Am J Physiol Cell Physiol. 2011;301(3):C695-C704. doi:10.1152/ajpcell.00322.2010
18. Cheng YC, Sheen JM, Hu WL, Hung YC. Polyphenols and oxidative stress in atherosclerosis-related ischemic heart disease and stroke. Oxid Med Cell Longev. 2017;2017:8526438. doi:10.1155/2017/8526438

19. Staerck C, Gastebois A, Vandeputte P, et al. Microbial antioxidant defense enzymes. Microb Pathog. 2017;110:56-65. doi:10.1016/j. micpath.2017.06.015

20. Morgan MJ, Liu Z. Crosstalk of reactive oxygen species and NFкB signaling. Cell Res. 2011;21(1):103-115. doi:10.1038/ cr.2010.178

21. Park K, Li Q, Evcimen ND, et al. Exogenous insulin infusion can decrease atherosclerosis in diabetic rodents by improving lipids, inflammation, and endothelial function. Arterioscler Thromb Vasc Biol. 2018;38(1):92-101. doi:10.1161/ATVBAHA.117.310291

22. Roth S, Singh V, Tiedt S, et al. Brain-released alarmins and stress response synergize in accelerating atherosclerosis progression after stroke. Sci Transl Med. 2018;10(432):eaao1313. doi:10.1126/scitranslmed.aao1313

23. Brandsma E, Kloosterhuis NJ, Koster $M$, et al. A proinflammatory gut microbiota increases systemic inflammation and accelerates atherosclerosis. Circ Res. 2019;124 (1):94-100. doi:10.1161/CIRCRESAHA.118.313234

24. Heger LA, Hortmann M, Albrecht M, et al. Inflammation in acute coronary syndrome: expression of TLR2 mRNA is increased in platelets of patients with ACS. PLoS One. 2019;14(10):e0224181. doi:10.1371/journal.pone.0224181

25. Szpak D, Grochowalski A, Chrząszcz R, et al. Tobacco smoke exposure and endothelial dysfunction in patients with advanced coronary artery disease. Pol Arch Med Wewn. 2013;123 (9):474-481. doi:10.20452/pamw.1889

26. Luchetti F, Crinelli R, Cesarini E, et al. Endothelial cells, endoplasmic reticulum stress and oxysterols. Redox Biol. 2017;13:581-587. doi:10.1016/j.redox.2017.07.014

27. Li XK, Zhang SF, Xu W, et al. Vascular endothelial injury in severe fever with thrombocytopenia syndrome caused by the novel bunyavirus. Virology. 2018;520:11-20. doi:10.1016/j. virol.2018.05.001

28. Crowther MA. Pathogenesis of atherosclerosis. ASH Educ Prog. 2005;2005:436-441.

29. Libby P, Ridker PM, Hansson GK. Progress and challenges in translating the biology of atherosclerosis. Nature. 2011;473 (7347):317-325. doi:10.1038/nature10146

30. Roy A, Saqib U, Wary K, Baig MS. Macrophage neuronal nitric oxide synthase (NOS1) controls the inflammatory response and foam cell formation in atherosclerosis. Int Immunopharmacol. 2020;83:106382. doi:10.1016/j.intimp.2020.106382

31. Chong $\mathrm{H}$, Wei Z, Na M, et al. The PGC-1 $\alpha / \mathrm{NRF} 1 / \mathrm{miR}-378 \mathrm{a}$ axis protects vascular smooth muscle cells from FFA-induced proliferation, migration and inflammation in atherosclerosis. Atherosclerosis. 2020;297:136-145. doi:10.1016/j.atherosclerosis.2020.02.001

32. Kang C, Li JL. Role of PGC-1 $\alpha$ signaling in skeletal muscle health and disease. Ann N Y Acad Sci. 2012;1271(1):110-117. doi:10.1111/j.1749-6632.2012.06738.x

33. Kadlec AO, Chabowski DS, Ait-Aissa K, et al. PGC-1alpha overexpression in coronary artery disease recruits nitric oxide and hydrogen peroxide during flow mediated dilation and protects against increased intraluminal pressure. Hypertension. 2017;70:166-173. doi:10.1161/HYPERTEN SIONAHA.117.09289

34. Kadlec AO, Chabowski DS, Ait-Aissa K, et al. Role of PGC- $1 \alpha$ in vascular regulation: implications for atherosclerosis. Arterioscler Thromb Vasc Biol. 2019;247:48-59.

35. Fukai T, Ushio-Fukai M. Superoxide dismutases: role in redox signaling, vascular function, and diseases. Antioxid Redox Signal. 2011;15(6):1583-1606. doi:10.1089/ars.2011.3999 
36. Berg G, Barchuk M, Miksztowicz V. Behavior of metalloproteinases in adipose tissue, liver and arterial wall: an update of extracellular matrix remodeling. Cells. 2019;8(2):158. doi:10.3390/cells8020158

37. Sherling DH, Perumareddi P, Hennekens CH. Metabolic syndrome: clinical and policy implications of the new silent killer. J Cardiovasc Pharmacol Ther. 2017;22(4):365-367. doi:10.1177/ 1074248416686187

38. Alberti KG, Eckel RH, Grundy SM, et al. Harmonizing the metabolic syndrome: a joint interim statement of the International Diabetes Federation Task Force on Epidemiology and Prevention; National Heart, Lung, and Blood Institute; American Heart Association; World Heart Federation; International Atherosclerosis Society; and International Association for the Study of Obesity. Circulation. 2009;120 (16):1640-1645. doi:10.1161/CIRCULATIONAHA.109.192644

39. Caimi G, Lo Presti R, Montana M, et al. Lipid peroxidation, nitric oxide metabolites, and their ratio in a group of subjects with metabolic syndrome. Oxid Med Cell Longev. 2014;2014:824756. doi: $10.1155 / 2014 / 824756$

40. Roberts CK, Sindhu KK. Oxidative stress and metabolic syndrome. Life Sci. 2009;84(21-22):705-712. doi:10.1016/j. lfs.2009.02.026

41. Marseglia L, Manti S, D'Angelo S, et al. Oxidative stress in obesity: a critical component in human diseases. Int J Mol Sci. 2015;16:378-400. doi:10.3390/ijms 16010378

42. Sottero B, Gargiulo S, Russo I, et al. Postprandial dysmetabolism and oxidative stress in type 2 diabetes: pathogenetic mechanisms and therapeutic strategies. Med Res Rev. 2015;35(5):968-1031. doi:10.1002/med.21349

43. Dzięgielewska-Gęsiak S, Płóciniczak A, WilemskaKucharzewska K, et al. The relationship between plasma lipids, oxidant-antioxidant status, and glycated proteins in individuals at risk for atherosclerosis. Clin Interv Aging. 2019;14:789-796. doi:10.2147/CIA.S196016

44. Khalfa A, Tiali A, Zemour L, et al. Prevalence of metabolic syndrome and its association with lifestyle and cardiovascular biomarkers among postmenopausal women in western Algeria. Int J Gynaecol Obstet. 2017;138(2):201-206. doi:10.1002/ijgo.12206

45. Klisic A, Kocic G, Kavaric N, et al. Nitric oxide products are not associated with metabolic syndrome. J Med Biochem. 2019;38 (3):361-367. doi:10.2478/jomb-2018-0035

46. Cani PD, Osto M, Geurts L, Everard A. Involvement of gut microbiota in the development of low-grade inflammation and type 2 diabetes associated with obesity. Gut Microbes. 2012;3 (4):279-288. doi:10.4161/gmic. 19625

47. Le Chatelier E, Nielsen T, Qin J, et al. Richness of human gut microbiome correlates with metabolic markers. Nature. 2013;500 (7464):541-546. doi:10.1038/nature12506

48. Halmos T, Suba I. Physiological patterns of intestinal microbiota. The role of dysbacteriosis in obesity, insulin resistance, diabetes and metabolic syndrome. Orv Hetil. 2016;157:13-22. doi:10.1556/650.2015.30296

49. Lazar V, Ditu LM, Pircalabioru GG, et al. Gut microbiota, host organism, and diet trialogue in diabetes and obesity. Front Nutr. 2019;6:21-26. doi:10.3389/fnut.2019.00021

50. Schunkert H, Moebus S, Hanisch J, et al. The correlation between waist circumference and ESC cardiovascular risk score: data from the German metabolic and cardiovascular risk project (GEMCAS). Clin Res Cardiol. 2008;97(11):827-835. doi:10.1007/s00392-0080694-1

51. Mancia G, Bombelli M, Facchetti R, et al. Impact of different definitions of the metabolic syndrome on the prevalence of organ damage, cardiometabolic risk and cardiovascular events. J Hypertens. 2010;28 (5):999-1006. doi:10.1097/HJH.0b013e328337a9e3
52. Adenan DM, Jaafar Z, Jayapalan JJ, Abdul Aziz A. Plasma antioxidants and oxidative stress status in obese women: correlation with cardiopulmonary response. PeerJ. 2020;8:e9230. doi: $10.7717 /$ peerj.9230

53. Frasca D, Blomberg BB, Paganelli R. Aging, obesity, and inflammatory age-related diseases. Front Immunol. 2017;8:1-10. doi:10.3389/fimmu.2017.01745

54. Zhang $\mathrm{T}$, Chen J, Tang $\mathrm{X}$, Luo Q, Xu D, Yu B. Interaction between adipocytes and high-density lipoprotein: newinsights into the mechanism of obesity-induced dyslipidemia and atherosclerosis. Lipids Health Dis. 2019;18(1):223. doi:10.1186/ s12944-019-1170-9

55. Lisko I, Tiainen K, Stenholm S, et al. Are body mass index, waist circumference and waist-to-hip ratio associated with leptin in 90-year-old people? Eur J Clin Nutr. 2013;67(4):420-422. doi:10.1038/ejcn.2013.39

56. Bonneau GA, Pedrozo WR, Berg G. Adiponectin and waist circumference as predictors of insulin-resistance in women. Diabetes Metab Syndr. 2014;8(1):3-7. doi:10.1016/j. dsx.2013.10.005

57. Alkaabi J, Gariballa S, Sharma C, et al. Inflammatory markers and cardiovascular risks among overweight-obese emirati women. BMC Res Notes. 2016;9(1):355. doi:10.1186/s13104-016-2160-x

58. Holewijn S, den Heijer M, van Tits LJ, Swinkels DW, Stalenhoef AF, de Graaf J. Impact of waist circumference versus adiponectin level on subclinical atherosclerosis: a cross-sectional analysis in a sample from the general population. J Intern Med. 2010;267(6):588-598. doi:10.1111/ j.1365-2796.2009.02192.x

59. Lee-Chang C, Bodogai M, Moritoh K, et al. Accumulation of 4-1BBL + B cells in the elderly induces the generation of granzyme-B $+\mathrm{CD} 8+\mathrm{T}$ cells with potential antitumor activity. Blood. 2014;124(9):1450-1459. doi:10.1182/blood-2014-03563940

60. Agarwal N, Chitrika A, Bhattacharjee J, Jain SK. Correlation of tumor necrosis factor- $\alpha$ and interleukin- 6 with anthropometric indices of obesity and parameters of insulin resistance in healthy north Indian population. JIACM. 2011;12(3):196-204.

61. Nieto-Vasquez I, Vern\{ndez-Veledo S, Kr\{mer DK, VilaBedmar R, Garcia-Guerra L, Lorenzo M. Insulin resistance associated to obesity: the link TNF-alpha. Arch Physiol Biochem. 2008;114(3):183-194. doi:10.1080/13813450802181047

62. Popko K, Gorska E, Stelmaszczyk-Emmel A, et al. Proinfl ammatory cytokines IL- 6 and TNF- $\alpha$ and the development of infl ammation in obese subjects. Eur J Med Res. 2010;15:120-122. doi:10.1186/2047-783X-15-S2-120

63. Efremov L, Lacruz ME, Tiller D, et al. Metabolically healthy, but obese individuals and associations with echocardiographic parameters and inflammatory biomarkers: results from the CARLA Study. Diabetes Metab Syndr Obes. 2020;13:2653-2665. doi:10.2147/DMSO.S263727

64. Adachi K, Sugiyama T, Yamaguchi Y, et al. Gut microbiota disorders cause type 2 diabetes mellitus and homeostatic disturbances in gut-related metabolism in Japanese subjects. J Clin Biochem Nutr. 2019;64:231-238. doi:10.3164/jcbn.18-101

65. Yadav D, Mishra M, Joseph AZ, et al. Status of antioxidant and lipid peroxidation in type 2 diabetic human subjects diagnosed with and without metabolic syndrome by using NCEP-ATPIII, IDF and WHO criteria. Obes Res Clin Pract. 2015;9(2):158-167. doi:10.1016/j.orcp.2014.03.004

66. Karaouzene N, Merzouk H, Aribi M, et al. Effects of the association of aging and obesity on lipids, lipoproteins and oxidative stress biomarkers: a comparison of older with young men. Nutr Metab Cardiovasc Dis. 2011;21(10):792-799. doi:10.1016/j. numecd.2010.02.007 
67. Schwingshackl L, Hoffmann G. Comparison of effects of long-term low-fat vs high-fat diets on blood lipid levels in overweight or obese patients: a systematic review and meta-analysis. $J$ Acad Nutr Diet. 2013;113(12):1640-1661. doi:10.1016/j. jand.2013.07.010

68. Hurtubise J, McLellan K, Durr K, Onasanya O, Nwabuko D, Ndisang JF. The different facets of dyslipidemia and hypertension in atherosclerosis. Curr Atheroscler Rep. 2016;18(12):82. doi:10.1007/s11883-016-0632-z

69. Rizzo M, Corrado E, Coppola G, Muratori I, Novo G, Novo S. Prediction of cardio- and cerebro-vascular events in patients with subclinical carotid atherosclerosis and low HDL-cholesterol. Atherosclerosis. 2008;200(2):389-395. doi:10.1016/j. atherosclerosis.2007.12.020

70. El Khoudary SR, Ceponiene I, Samargandy S, et al. HDL (High-Density Lipoprotein) metrics and atherosclerotic risk in women. Arterioscler Thromb Vasc Biol. 2018;38(9):2236-2244. doi:10.1161/ATVBAHA.118.311017

71. Lehto S, Ronnemaa T, Pyorala K, Laakso M. Cardiovascular risk factors clustering with endogenous hyperinsulinaemia predict death from coronary heart disease in patients with type II diabetes. Diabetologia. 2000;43:148-155. doi:10.1007/s001250050023

72. Rutter MK, Meigs JB, Sullivan LM, et al. Insulin resistance, the metabolic syndrome, and incident cardiovascular events in the Framingham Offspring Study. Diabetes. 2005;54(11):3252-3257. doi:10.2337/diabetes.54.11.3252

73. Millan J, Pinto X, Munoz A, et al. Lipoprotein ratios: physiological significance and clinical usefulness in cardiovascular prevention. Vasc Health Risk Manag. 2009;5:757-765.

74. Dobiasova M. AIP-atherogenic index of plasma as a significant predictor of cardiovascular risk: from research to practice [AIPaterogenní index plazmy jako významný prediktor kardiovaskularního rizika: od výzkumu do praxe]. Vnitr Lek. 2006;52(1):64-71.

75. Zhu XW, Deng FY, Lei SF. Meta-analysis of atherogenic index of plasma and other lipid parameters in relation to risk of type 2 diabetes mellitus. Prim Care Diabetes. 2015;9(1):60-67. doi:10.1016/j.pcd.2014.03.007

76. Polonskaya YV, Shramko VS, Morozov SV, Chernyak EI, Chernyavsky AM, Ragino YI. Balance of fatty acids and their correlations with parameters of lipid metabolism and markers of inflammation in men with coronary atherosclerosis. Bull Exp Biol Med. 2017;164(1):33-35. doi:10.1007/s10517-017-3920-x

77. Zheng JS, Sharp SJ, Imamura F, et al. Association between plasma phospholipid saturated fatty acids and metabolic markers of lipid, hepatic, inflammation and glycaemic pathways in eight European countries: a cross-sectional analysis in the EPIC-InterAct study. BMC Med. 2017;15(1):203. doi:10.1186/ s12916-017-0968-4

78. Hadj Ahmed S, Kharroubi W, Kaoubaa N, et al. Correlation of trans fatty acids with the severity of coronary artery disease lesions. Lipids Health Dis. 2018;17(1):52. doi:10.1186/s12944-018-0699-3

79. Decharatchakul N, Settasatian C, Settasatian N, et al. Association of genetic polymorphisms in SOD2, SOD3, GPX3, and GSTT1 with hypertriglyceridemia and low HDL-C level in subjects with high risk of coronary artery disease. PeerJ. 2019;7:e7407. doi: 10.7717 peerj. 7407

80. Dzięgielewska-Gęsiak S, Bielawska L, Zowczak-Drabarczyk M, et al. The impact of high-density lipoprotein on oxidant-antioxidant balance in healthy elderly people. Pol Arch Med Wewn. 2016;126(10):731-738. doi:10.20452/pamw.3559

81. Singh K, Singh R, Chandra S, Tyagi S. Paraoxonase-1 is a better indicator than HDL of atherosclerosis - a pilot study in North Indian population. Diabetes Metab Syndr. 2018;12(3):275-278. doi:10.1016/j.dsx.2017.12.006
82. Hao W, Friedman A. The LDL-HDL profile determines the risk of atherosclerosis: a mathematical model. PLoS One. 2014;9(3): e90497. doi:10.1371/journal.pone.0090497

83. Formanowicz D, Krawczyk JB, Perek B, Formanowicz P. A control-theoretic model of atherosclerosis. Int $J$ Mol Sci. 2019;20(3):785. doi:10.3390/ijms20030785

84. Paun A, Danska JS. Modulation of type 1 and type 2 diabetes risk by the intestinal microbiome. Pediatr Diabetes. 2016;17:469-476. doi:10.1111/pedi.12424

85. Ruotsalainen E, Salmenniemi U, Vauhkonen I, et al. Changes in Inflammatory cytokines are related to impaired glucose tolerance in Offspring of type 2 diabetic subjects. Diabetes Care. 2006;29 (12):2714-2720. doi:10.2337/dc06-0147

86. Woo CY, Jang JE, Lee SE, Koh EH, Lee KU. Mitochondrial dysfunction in adipocytes as a primary cause of adipose tissue inflammation. Diabetes Metab J. 2019;43:247-256. doi:10.4093/ dmj.2018.0221

87. Saukkonen T, Mutt SJ, Jokelainen J, et al. Adipokines and inflammatory markers in elderly subjects with high risk of type 2 diabetes and cardiovascular disease. Sci Rep. 2018;8(1):12816. doi:10.1038/s41598-018-31144-8

88. Rizza S, Cardellini M, Martelli E, et al. Occult impaired glucose regulation in patients with atherosclerosis is associated to the number of affected vascular districts and inflammation. Atherosclerosis. 2010;212(1):316-320. doi:10.1016/j. atherosclerosis.2010.05.017

89. Wu W, Wang M, Sun Z, Wang X, Miao J, Zheng Z. The predictive value of TNF- $\alpha$ and IL- 6 and the incidence of macrovascular complications in patients with type 2 diabetes. Acta Diabetol. 2012;49(1):3-7. doi:10.1007/s00592-010-0198-0

90. Kontush A, Chapman MJ. Antiatherogenic function of HDL particle subpopulations: focus on antioxidative activities. Curr Opin Lipidol. 2010;21:312-318. doi:10.1097/MOL.0b013e32833bcdc1

91. Dullaart RP, Annema W, Tio RA, Tietge UJ. The HDL anti-infammatory function is impaired in myocardial infarction and may predict new cardiac events independent of HDL cholesterol. Clin Chim Acta. 2014;433:34-38. doi:10.1016/j. cca.2014.02.026

92. Ebtehaj S, Gruppen EG, Parvizi M, Tietge UJF, Dullaart RPF. The anti-inflammatory function of HDL is impaired in type 2 diabetes: role of hyperglycemia, paraoxonase-1 and low grade inflammation. Cardiovasc Diabetol. 2017;16(1):132. doi:10.1186/s12933-017-0613-8

93. Hernaez A, Soria-Florido MT, Schröder H, et al. Role of HDL function and LDL atherogenicity on cardiovascular risk: a comprehensive examination. PLoS One. 2019;14(6):e0218533. doi:10.1371/journal.pone. 0218533

94. Dzięgielewska-Gęsiak S, Wysocka E, Michalak S, NowakowskaZajdel E, Kokot T, Muc-Wierzgoń M. Role of lipid peroxidation products, plasma total antioxidant status, and $\mathrm{Cu}$-, $\mathrm{Zn}$-superoxide dismutase activity as biomarkers of oxidative stress in elderly prediabetics. Oxid Med Cell Longev. 2014;2014:987303. doi: $10.1155 / 2014 / 987303$

95. Kozakova M, Morizzo C, Goncalves I, Natali A, Nilsson J, Palombo C. Cardiovascular organ damage in type 2 diabetes mellitus: the role of lipids and inflammation. Cardiovasc Diabetol. 2019;18(1):61. doi:10.1186/s12933-019-0865-6

96. Manabe S, Okura T, Watanabe S, Higaki J. Association between carotid haemodynamics and inflammation in patients with essential hypertension. J Hum Hypertens. 2005;19(10):787-791. doi:10.1038/sj.jhh.1001898

97. Caimi G, Mulè G, Hopps E, Carollo C, Lo Presti R. Nitric oxide metabolites and oxidative stress in mild essential hypertension. Clin Hemorheol Microcirc. 2010;46(4):321-325. doi:10.3233/ CH-2010-1360 
98. Saraswathi R, Sankar D, Ali A, et al. A pilot assessment of oxidative stress byproducts and antioxidant activities among Indian patients with various stages of hypertension. Clin Exp Hypertens. 2011;33(7):437-443. doi:10.3109/10641963.2010. 549259

99. Cao J, Wang HY. Association between total antioxidant status and atherosclerosis in elderly patients with essential hypertension. Zhonghua Xin Xue Guan Bing Za Zhi. 2013;41(10):857-861.

100. Kaypaklı O, Gür M, Harbalıoğlu H, Şeker T, Selek Ş. High morning blood pressure surge is associated with oxidative stress and paraoxonase 1 activity in newly diagnosed hypertensive patients. Clin Exp Hypertens. 2016;38(8):680-685. doi:10.1080/ 10641963.2016.1200602

101. Gómez-Marcos MA, Blazquez-Medela AM, Gamella-Pozuelo L, Recio-Rodriguez JI, García-Ortiz L, Martínez-Salgado C. Serum superoxide dismutase is associated with vascular structure and function in hypertensive and diabetic patients. Oxid Med Cell Longev. 2016;2016:9124676. doi:10.1155/2016/9124676

102. Kou H, Deng J, Gao D, et al. Relationship among adiponectin, insulin resistance and atherosclerosis in non-diabetic hypertensive patients and healthy adults. Clin Exp Hypertens. 2018;40 (7):656-663. doi:10.1080/10641963.2018.1425414

103. David S, Kümpers P, Lukasz A, Kielstein JT, Haller H, Fliser D. Circulating angiopoietin-2 in essential hypertension: relation to atherosclerosis, vascular inflammation, and treatment with olmesartan/pravastatin. $J$ Hypertens. 2009;27(8):1641-1647. doi:10.1097/HJH.0b013e32832be575

104. Lakoski SG, Cushman M, Siscovick DS, et al. The relationship between inflammation, obesity and risk for hypertension in the Multi-Ethnic Study of Atherosclerosis (MESA). J Hum Hypertens. 2011;25(2):73-79. doi:10.1038/jhh.2010.91

105. Jayedi A, Rahimi K, Bautista LE, Nazarzadeh M, Zargar MS, Shab-Bidar S. Inflammation markers and risk of developing hypertension: a meta-analysis of cohort studies. Heart. 2019;105 (9):686-692. doi:10.1136/heartjnl-2018-314216

106. Takagi T, Naito Y, Kashiwagi S, et al. Changes in the gut microbiota are associated with hypertension, hyperlipidemia, and type 2 diabetes mellitus in Japanese subjects. Nutrients. 2020;12 (10):2996-3004. doi:10.3390/nu12102996

107. Dziechciaż M, Filip R. Biological psychological and social determinants of old age: bio-psycho-social aspects of human aging. Ann Agric Environ Med. 2014;21(4):835-838. doi:10.5604/ 12321966.1129943

108. Harman D. Free radicals in aging. Mol Cell Biochem. 1988;84 (2):155-161. doi:10.1007/BF00421050

109. Camandola S, Mattson MP. Brain metabolism in health, aging, and neurodegeneration. EMBO J. 2017;36(11):1474-1492. doi:10.15252/embj.201695810

110. Afilalo J, Alexander KP, Mack MJ, et al. Frailty assessment in the cardiovascular care of older adults. J Am Coll Cardiol. 2014;63 (8):747-762. doi:10.1016/j.jacc.2013.09.070

111. Malczyk E, Dzięgielewska-Gęsiak S, Fatyga E, Ziółko E, Kokot T, Muc-Wierzgoń M. Body composition in healthy older persons: role of the ratio of extracellular/total body water. $J$ Biol Regul Homeost Agents. 2016;30(3):767-772.

112. Potes Y, de Luxan-delgado B, Rodriguez-Gonzalez S, et al. Overweight in elderly people induces impaired autophagy in skeletal muscle. Free Radic Biol Med. 2017;110:31-41. doi:10.1016/j.freeradbiomed.2017.05.018

113. Lee HY, Zeeshan HMA, Kim HR, et al. Nox4 regulates the eNOS uncoupling process in aging endothelial cells. Free Radic Biol Med. 2017;113:26-35. doi:10.1016/j.freeradbiomed.2017.09.010

114. Gates PE, Strain WD, Shore AC. Human endothelial function and microvascular ageing. Exp Physiol. 2009;94(3):311-316. doi:10.1113/expphysiol.2008.043349
115. Lassegue B, San Martin A, Griendling KK. Biochemistry, physiology, and pathophysiology of NADPH oxidases in the cardiovascular system. Circ Res. 2012;110(10):1364-1390. doi:10.1161/ CIRCRESAHA.111.243972

116. Judkins CP, Diep H, Broughton BR, et al. Direct evidence of a role for Nox2 in superoxide production, reduced nitric oxide bioavailability, and early atherosclerotic plaque formation in ApoE-/- mice. Am J Physiol Heart Circ Physiol. 2010;298: H24-H32. doi:10.1152/ajpheart.00799.2009

117. Silva JF, Correa IC, Diniz TF, et al. Obesity, inflammation, and exercise training: relative contribution of iNOS and eNOS in the modulation of vascular function in the mouse aorta. Front Physiol. 2016;7(386):1-13. doi:10.3389/fphys.2016.00386

118. Xiong S, Patrushev N, Forouzandeh F, et al. PGC- $1 \alpha$ modulates telomere function and DNA damage in protecting against agingrelated chronic diseases. Cell Rep. 2015;12(9):1391-1399. doi:10.1016/j.celrep.2015.07.047

119. Salazar G, Cullen A, Huang J, et al. SQSTM1/p62 and PPARGC1A/PGC-1alpha at the interface of autophagy and vascular senescence. Autophagy. 2020;16(6):1092-1110. doi:10.1080/15548627.2019.1659612

120. Varghese JF, Patel R, Yadav UCS. Novel insights in the metabolic syndrome-induced oxidative stress and inflammation-mediated atherosclerosis. Curr Cardiol Rev. 2018;14:4-14. doi:10.2174/ 1573403X13666171009112250

121. Dzięgielewska-Gęsiak S, Stołtny D, Brożek A, Muc-Wierzgoń M, Wysocka E. Are insulin-resistance and oxidative stress cause or consequence of aging. Exp Biol Med (Maywood). 2020;245 (14):1260-1267. doi:10.1177/1535370220929621

122. Yadav R, Yadav RK, Khadgawat R, Pandey RM. Comparative efficacy of a 12 week yoga-based lifestyle intervention and dietary intervention on adipokines, inflammation, and oxidative stress in adults with metabolic syndrome: a randomized controlled trial. Transl Behav Med. 2019;9(4):594-604. doi:10.1093/tbm/iby060

123. Beydoun MA, Fanelli-Kuczmarski MT, Beydoun HA, et al. Dairy product consumption and its association with metabolic disturbance in a prospective study of urban adults. Br J Nutr. 2018;119 (6):706-719. doi:10.1017/S0007114518000028

124. Guasch-Ferré M, Babio N, Martínez-Gonz\{lez MA, et al. Dietary fat intake and risk of cardiovascular disease and all-cause mortality in a population at high risk of cardiovascular disease. $\mathrm{Am}$ J Clin Nutr. 2015;102(6):1563-1573. doi:10.3945/ ajen.115.116046

125. Usharani P, Merugu PL, Nutalapati C. Evaluation of the effects of a standardized aqueous extract of Phyllanthus emblica fruits on endothelial dysfunction, oxidative stress, systemic inflammation and lipid profile in subjects with metabolic syndrome: a randomised, double blind, placebo controlled clinical study. BMC Complement Altern Med. 2019;19(1):97. doi:10.1186/ s12906-019-2509-5

126. Song J, Huang Y, Zheng W, et al. Resveratrol reduces intracellular reactive oxygen species levels by inducing autophagy through the AMPK-mTOR pathway. Front Med. 2018;12 (6):697-706. doi:10.1007/s11684-018-0655-7

127. Bagul PK, Deepthi N, Sultana R, Banerjee SK. Resveratrol ameliorates cardiac oxidative stress in diabetes through deacetylation of NFkB-p65 and histone 3. J Nutr Biochem. 2015;26:1298-1307. doi:10.1016/j.jnutbio.2015.06.006

128. Timmers S, Konings E, Bilet L, et al. Calorie restriction-like effects of 30 days of resveratrol supplementation on energy metabolism and metabolic profile in obese humans. Cell Metab. 2011;14:612-622. doi:10.1016/j.cmet.2011.10.002

129. Fontana L, Villareal DT, Das SK, et al. Effects of 2-year calorie restriction on circulating levels of IGF-1, IGF-binding proteins and cortisol in nonobese men and women: a randomized clinical trial. Aging Cell. 2016;15:22-27. doi:10.1111/acel.12400 
130. Villareal DT, Aguirre L, Gurney AB, et al. Aerobic or resistance exercise, or both, in dieting obese older adults. $N$ Engl $J$ Med. 2017;376(20):1943-1955. doi:10.1056/NEJMoa1616338

131. Illan-Gómez F, Gonzalvez-Ortega M, Orea-Soler I, et al. Obesity and inflammation: change in adiponectin, $\mathrm{C}$-reactive protein, tumour necrosis factor-alpha and interleukin-6 after bariatric surgery. Obes Surg. 2012;22(6):950-955. doi:10.1007/s11695-012-0643-y

132. Huang Y, Zhu X, Chen K, et al. Resveratrol prevents sarcopenic obesity by reversing mitochondrial dysfunction and oxidative stress via the PKA/LKB1/AMPK pathway. Aging. 2019;11:2217-2240. doi:10.18632/aging.101910

133. Solomon TP, Sistrun SN, Krishnan RK, et al. Exercise and diet enhance fat oxidation and reduce insulin resistance in older obese adults. J Appl Physiol. 2008;104(5):1313-1319. doi:10.1152/ japplphysiol.00890.2007

134. Rom O, Volkova N, Jeries H, Grajeda-Iglesias C, Aviram M. Exogenous (Pomegranate juice) or Endogenous (Paraoxonase1) antioxidants decrease triacylglycerol accumulation in mouse cardiovascular disease-related tissues. Lipids. 2018;53(1112):1031-1041. doi:10.1002/lipd.12112

135. Wielkoszyński T, Zalejska-Fiolka J, Strzelczyk JK, et al. Oxysterols increase inflammation, lipid marker levels and reflect accelerated endothelial dysfunction in experimental animals. Mediators Inflamm. 2018;ID 2784701. doi:10.1155/2018/2784701

136. Verhoeven V, Van der Auwera A, Van Gaal L, et al. Can red yeast rice and olive extract improve lipid profile and cardiovascular risk in metabolic syndrome?: a double blind, placebo controlled randomized trial. BMC Complement Altern Med. 2015;15:52. doi:10.1186/s12906-015-0576-9

137. Zhu X, Yang J, Zhu W, et al. Combination of berberine with resveratrol improves the lipid-lowering efficacy. Int $J \mathrm{Mol} \mathrm{Sci}$. 2018;19(12):3903. doi:10.3390/ijms 19123903

138. Gabriel B, Ratkevicius A, Gray P, Frenneaux MP, Gray SR. Highintensity exercise attenuates postprandial lipaemia and markers of oxidative stress. Clin Sci. 2012;123(5):313-321. doi:10.1042/ CS20110600

139. Sawada T, Tsubata H, Hashimoto N, et al. Effects of 6-month eicosapentaenoic acid treatment on postprandial hyperglycemia, hyperlipidemia, insulin secretion ability, and concomitant endothelial dysfunction among newly-diagnosed impaired glucose metabolism patients with coronary artery disease. An open label, single blinded, prospective randomized controlled trial. Cardiovasc Diabetol. 2016;15(1):121. doi:10.1186/s12933-016-0437-y

140. Kim H, Simbo SY, Fang C, et al. Açaí (Euterpe oleracea Mart.) beverage consumption improves biomarkers for inflammation but not glucose- or lipid-metabolism in individuals with metabolic syndrome in a randomized, double-blinded, placebo-controlled clinical trial. Food Funct. 2018;9(6):3097-3103. doi:10.1039/ c8fo00595h
141. Farabi SS, Carley DW, Smith D, Quinn L. Impact of exercise on diurnal and nocturnal markers of glycaemic variability and oxidative stress in obese individuals with type 2 diabetes or impaired glucose tolerance. Diab Vasc Dis Res. 2015;12(5):381-385. doi: $10.1177 / 1479164115579003$

142. Johnson SA, Figueroa A, Navaei N, et al. Daily blueberry consumption improves blood pressure and arterial stiffness in postmenopausal women with pre- and stage 1-hypertension: a randomized, double-blind, placebo-controlled clinical trial. J Acad Nutr Diet. 2015;115(3):369-377. doi:10.1016/j.jand.2014.11.001

143. Choy KW, Lau YS, Murugan D, Mustafa MR, Bader M. Chronic treatment with paeonol improves endothelial function in mice through inhibition of endoplasmic reticulum stress-mediated oxidative stress. PLoS One. 2017;12(5):e0178365. doi:10.1371/journal.pone. 0178365

144. Barili A, Corralo VDS, Cardoso AM, et al. Acute responses of hemodynamic and oxidative stress parameters to aerobic exercise with blood flow restriction in hypertensive elderly women. $\mathrm{Mol}$ Biol Rep. 2018;45(5):1099-1109. doi:10.1007/s11033-018-4261-1

145. Dolati S, Namiranian K, Amerian R, et al. The effect of curcumin supplementation and aerobic training on anthropometric indices, serum lipid profiles, C-reactive protein and insulin resistance in overweight women: a randomized, double-blind, placebo-controlled trial. J Obes Metab Syndr. 2020;29(1):47-57. doi:10.7570/jomes19055

146. Welty FK, Alfaddagh A, Elajami TK. Targeting inflammation in metabolic syndrome. Transl Res. 2016;167:257-280.

147. Kelany ME, Hakami TM, Omar AH. Curcumin improves the metabolic syndrome in high-fructose-diet-fed rats: role of TNF$\alpha$, NF-kB, and oxidative stress. Can J Physiol Pharmacol. 2017;95:140-150. doi:10.1139/cjpp-2016-0152

148. Dogaru G, Bulboaca AE, Gheban D, et al. Effect of liposomal curcumin on acetaminophen hepatotoxicity by down-regulation of oxidative stress and matrix metalloproteinases. In Vivo. 2020;34 (2):569-582. doi:10.21873/invivo.11809

149. Maithilikarpagaselvi N, Sridhar MG, Swaminathan RP, Zachariah B. Curcumin prevents inflammatory response, oxidative stress and insulin resistance in high fructose fed male wistar rats: potential role of serine kinases. Chem Biol Interact. 2016;244:187-194. doi:10.1016/j.cbi.2015.12.012

\section{Publish your work in this journal}

Clinical Interventions in Aging is an international, peer-reviewed journal focusing on evidence-based reports on the value or lack thereof of treatments intended to prevent or delay the onset of maladaptive correlates of aging in human beings. This journal is indexed on PubMed Central, MedLine, CAS, Scopus and the Elsevier
Bibliographic databases. The manuscript management system is completely online and includes a very quick and fair peer-review system, which is all easy to use. Visit http://www.dovepress.com/ testimonials.php to read real quotes from published authors. 